\title{
The Erskine House Tree: closing the loop on my medical roots
}

\author{
— Cite as: CMAJ 2019 February 25;191:E235-7. doi: 10.1503/cmaj.180693
}

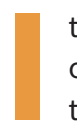

$\mathrm{t}$ is rare that you get to close the loop on something your father did more than 50 years ago. My father, who passed away in 2012, had always encouraged his children to have a child, write a book and plant a tree. I have yet to write a book, but I have 2 sons and I had been looking for an appropriate location to plant a tree in my father's memory. Then, in the summer of 2017, 2 physicians from Belfast, Ireland, connected with my brother via Facebook and asked if a member of our family would attend a ceremony to rededicate a tree that my father had planted on the grounds of the Belfast City Hospital where he had worked as a nephrology fellow (1966-1969).

My father, Dimitrios Oreopoulos (19362012), graduated from the University of Athens, completed training in internal medicine and nephrology, and, in 1966, was accepted as a fellow by Dr. Molly McGeown at Queen's University Belfast to complete an MD thesis on metabolic renal stone and bone disease. As a young Greek physician without an academic record and who barely spoke English, my father considered himself especially lucky to have this opportunity. To show his gratitude to the medical school, he brought with him 4 seeds from the Oriental plane tree on the Greek island of Kos under which it is asserted that Hippocrates sat and taught his students (the tree on the island of Kos is about 500 years old and, therefore, most likely a descendent of the original). These were planted on the grounds of the Belfast City Hospital, where 1 still survives, standing next to a nurses' residence called "The Erskine House."

After completing his training in Ireland, my father was accepted on a Commonwealth Medical Scholarship to continue training in Toronto. He later

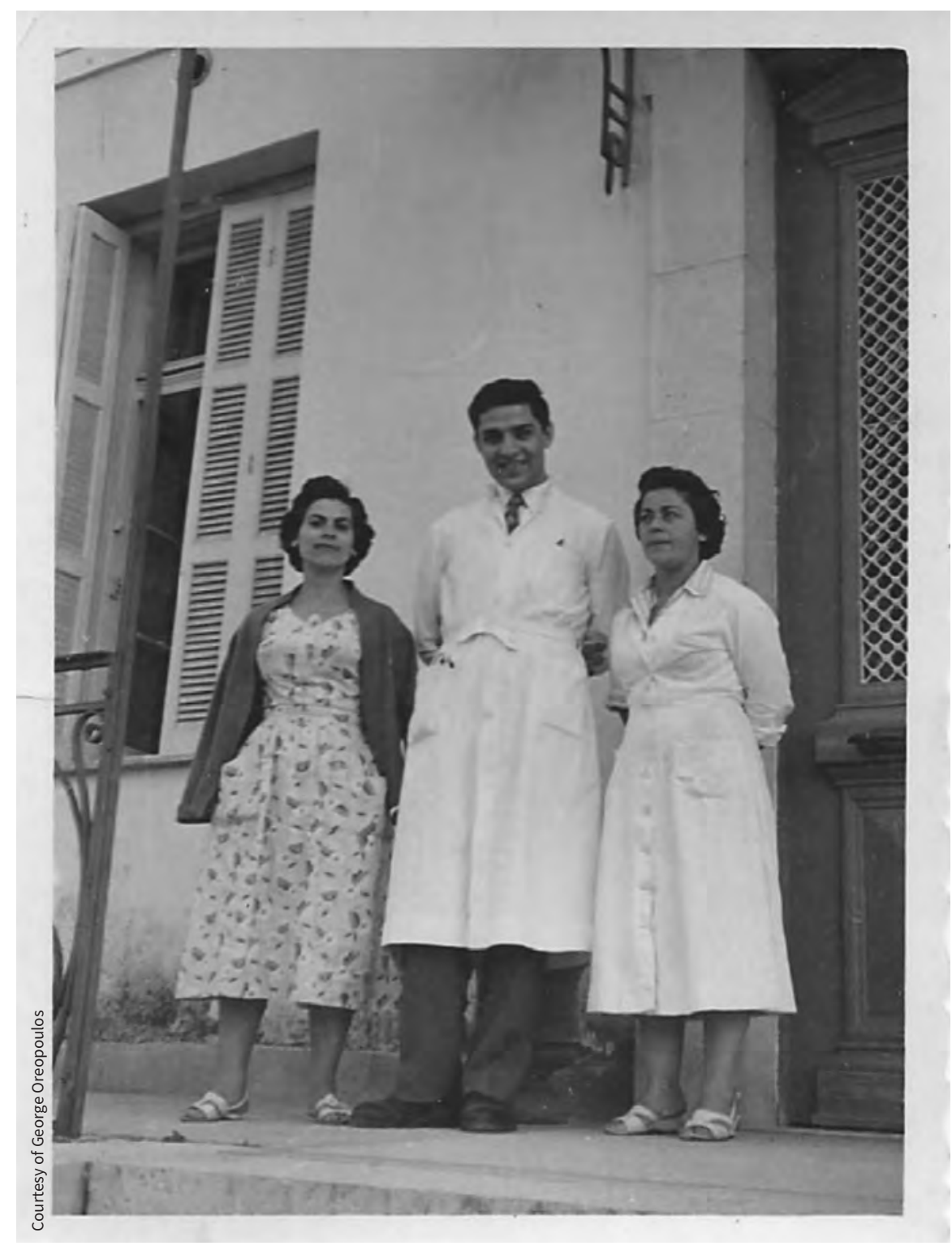

Dimitrios Oreopoulos as a nephrology trainee in Greece, early 1960s.

developed continuous ambulatory peritoneal dialysis, a treatment that is still used worldwide to preserve the lives of patients with end-stage renal disease. His academic interests spanned all aspects of peritoneal dialysis and he went on to pioneer subspecialties including geriatric nephrology and nephroprevention.

Throughout his career, my father maintained a strong belief that patients need to 


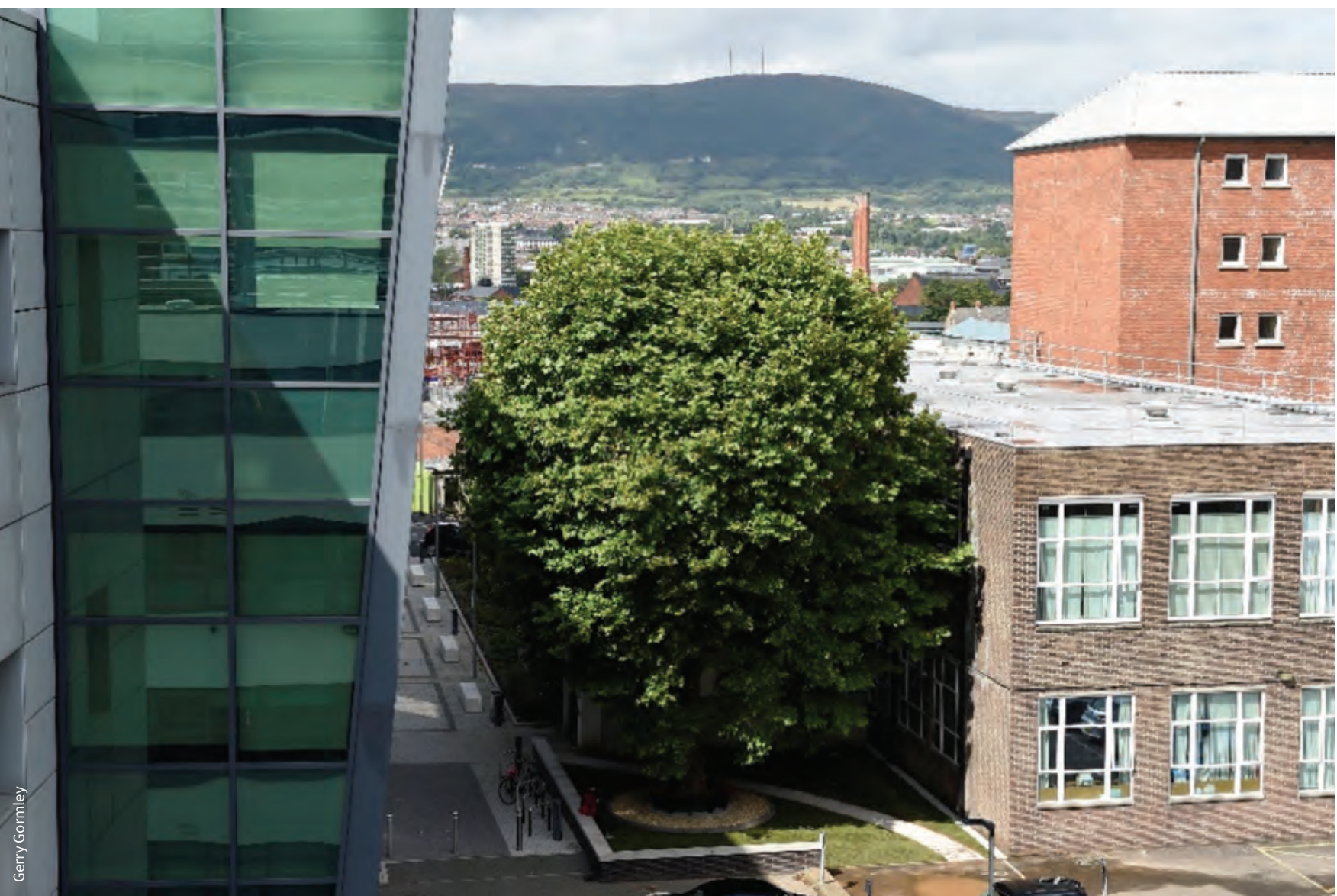

The Erskine House Tree, Queen's University, Belfast, Ireland, 2017.

remain at the centre of physicians' efforts despite trends and medical advances that threaten to industrialize care. In the time of Hippocrates, physicians had little more than their presence and bedside manner with which to treat patients; my father believed that strong doctor-patient relationships were at the core of his identity as a physician. Nephrologists may see their patients in the dialysis unit up to 3 times a week over the course of years. My father formed many long-term relationships. It was not uncommon for him to visit patients when they were admitted to outside hospitals, occasionally at their homes, and to attend their funerals when there was no more care to give.

As withdrawal of dialysis and palliative care is a reality for patients with end-stage comorbidities and poor quality of life, my father became interested in empowering patients in their decision-making about life-sustaining treatment, as well as the dignified and ethical care of dying patients. Humane medicine was the subject of a June 1,1983 , editorial in CMAJ. ${ }^{1}$
My father formed the Humane Medicine Journal in 1984. The articles of incorporation stated that the journal was developed, "To promote humanity and caring in the practice of medicine" and "To provide a forum for communication and exchange of ideas, experiences and insights among health care professionals who desire to improve themselves and the type of care they are offering." The journal was successful in that it started a conversation about ethical and humane medical care before medical humanities became fashionable. Through the same corporation, my father also financially supported patients who were uninsured for their medical care and helped nephrology fellows who could not afford to travel to Canada for training.

At the end of his life, he had published more than 600 articles and had trained more than 200 nephrology fellows from all over the world, including India, Greece and China. Many were guests at our family dinner table. My father explained that as an immigrant, he understood the challenges of language and cultural barriers.
Just as my father's former trainees have branched out across the world to practise and teach, multiple cuttings from his "original" Plane Tree of Kos (of which there are at least 25) have been transplanted to other medical institutions. The remaining tree in Belfast has become known as the Erskine House Tree. It is situated beside Queen's Institute for Experimental Medicine. ${ }^{2}$ The tree has become a symbol of hope as well as medical humanism. It has also become a rallying point for those advocating for changes to Irish law to promote better access to organ transplantation. To safeguard and recognize the tree, Queen's championed it for the United Kingdom's Woodland Trust Tree of the Year competition, which it won in 2017.

At a personal level, it is not clear to me when the idea to pursue medicine as a career took root in my mind. Some days, I wonder if it was "planted" there by my father. My earliest memory of a hospital was when I accompanied him on rounds in the dialysis unit. I was barely tall enough to see above the end of a hospital 
bed. Like many Greeks, I carry a strong sense of family history. Hanging in my office, beside my father's medical degree, is my great grandfather's original medical license to practise throughout the Ottoman Empire, bestowed in 1918. Thus, the Erskine House Tree represents my own familial, cultural and professional "roots."

On Oct. 26, 2017, I travelled to Belfast with my son Dimitrios, who had been exceptionally close to his grandfather. I was stunned at the size of the tree that threatens to dwarf adjacent buildings. It reminded me of the giant in my life who planted it. Its location beside the institute is a reminder of the need for medical humanism to go hand in hand with technological advancement.

Present at the tree's rededication were representatives of the university and the medical school, and renal patients and their families. Former staff told me about the importance of nursing engagement and team collaboration, as well as the willingness to accept international trainees and share what the group had learned. These same elements were important to the success and innovation of my father's peritoneal dialysis unit in Toronto. Inspired by him, I have done my best to promote the interests of international vascular surgery trainees at the University of Toronto and have trained surgeons from Saudi Arabia, Mexico, the Philippines and the Carribean, as well as the UK and Ireland.

The Erskine House Tree represents medicine's continunity throughout the ages and is the embodiment of Hippocrates' quote, "Life is short, the art is long."3

I thought it was important for my own son to understand that human beings cannot necessarily predict the good that can come from their actions and that even small acts of gratitude or kindness can have lasting positive effects long after we are gone. This trip may have given me the opportunity to plant an idea that will allow a new branch to grow from my own medical family's "tree."

\section{George D. Oreopoulos MD MSc}

Divisions of Vascular Surgery and Vascular Interventional Radiology, University Health Network; Departments of Surgery and Medical Imaging, University of Toronto; Humane Medicine Inc., Toronto, Ont.

\section{References}

1. Oreopoulos DG. Humane medicine [editorial]. CMAJ 1983;128:1279-80.

2. Douglas JF. Dimitrios Oreopoulos, The Plane Tree of Kos and Belfast City Hospital. Ulster Med J 2014;83:31-6.

3. Hippocrates. Aphorisms, written 400 B.C.E., translated by Francis Adams. In: The Internet Classics Archive 1994-2009; Section 1, number 1.

This article has been peer reviewed. 